\title{
SISTEM PAKAR MENGGUNAKAN METODE FORWARD CHAINING DAN METODE CERTAINTY FACTOR UNTUK MENDIAGNOSA TAHAPAN PENGGUNA NARKOBA
}

\author{
Ahmad Taufik \\ Universitas Bina Sarana Informatika \\ Jakarta, (+021) 8000063 \\ Email: ahmad.tad@bsi.ac.id
}

\begin{abstract}
Abstrak
Narkoba telah menjadi musuh yang sangat nyata hingga saat ini, tidak hanya bagi orang-orang yang menggunakan narkoba ini, tetapi juga semua aspek kehidupan konstitusional bahkan ke seluruh dunia, karena narkoba termasuk dalam kategori tindakan kriminal yang sangat berbahaya. Di sisi lain, para pelaku narkoba juga ingin hidup kembali seperti sebelumnya yang benar-benar terpisah dari perangkap narkoba, tetapi mereka merujuk pada lingkungan sekitar dan biaya minimal untuk melakukan rehabilitasi media.

Oleh karena itu, untuk dapat mengetahui jumlah pengguna narkoba, maka, Para Ahli membuat konsep sistem Pakar dengan metode Forward Chaining, Certainty Factor, dengan menggunakan bahasa pemrograman PHP dan database MySQL. Dengan sistem ini, para ahli diharapkan dapat mengetahui tingkat persepsi pengguna narkoba serta mengetahui kemungkinan penanganan tindakan.
\end{abstract}

Kata Kunci: Sistem Pakar, Forwad Chaining, Certainty Factor, Narkotika

\begin{abstract}
Drugs have become very real enemies to the present day, not just for people who use these drugs, but also all aspects of constitutional life even to the whole world, because drugs are included in the category of criminal acts that are very dangerous. On the other hand, the perpetrators of drugs also want to return to life like before that are completely separate from the trap of drugs, but they referred to the surrounding environment and the minimal cost of doing media rehabilitation.

Therefore, to be able to know the number of drug users, then, the Experts make the concept of an Expert system with Forward Chaining method, Certainty Factor, by using PHP programming language and MySQL database. With this system, Experts are expected to be able to know the level of drug users perceived levels as well as know the possibility of action handling.
\end{abstract}

\section{Keywords: Expert System, Forward Chaining, Certainty Factor, Drugs}

\section{Pendahuluan}

IImu pengetahuan tentang IT dimasa sekarang ini, sangat berpengaruh dalam sebagian besar aspek kinerja manusia. Kemajuan teknologi yang berkembang tiap tahun nya, semakin menafsirkan bahwa teknologi informasi dapat menjadi sarana dalam penyelesaian suatu pekerjaan, dan komputer merupakan sarana pendukung yang digunakan dalam proses penunjang kinerja tersebut.

Napza sendiri yaitu kepanjangan dari narkotika, psikotropika, dan bahan adiktif beserta kandungannya, bisa dikatakan merupakan sekumpulan jenis obat-obatan terlarang/ilegal, yang bisa mempengaruhi kineja organ tubuh, otak atau syaraf serta menyebabkan dampak gangguan yang nyata di dalam kesehatan baik fisik, mental, sosial, karena adanya senyawa yang memunculkan sifat adiksi dan dependensi bagi penggunanya.

Bahkan untuk saat ini narkoba/napza bukan hanya beredar dikota besar tetapi mulai masuk dipedesaan bahkan semua jenis golongan masyarakat (Sergey A, Mityagin. et al, 2014)

Dengan mengetahui sebuah tingkatan pengguna narkoba, aplikasi sistem pakar yang dirancang ini nantinya diharapkan mampu memberi jawaban yang relevan 
mengenai cara penanggulangan dan pencegahannya. Dalam melakukan diagnosa, seorang pakar kadang mengalami kekurangan dan keterbatasan data dalam menentukan keputusan. Agar sistem dapat melakukan pemahaman dalam menganalisa sebuah data, meskipun data yang ada tidak lengkap atau belum pasti, maka sistem harus menggunakan pemodelan yang dinamakan dengan metode Faktor Kepastian(Certainty Factor). Certainty Factor adalah metode dalam menentukan derajat kepercayaan user terhadap sistem pakar. Metode Certainty Factor berfungsi memberikan hasil dari setiap analisa dalam bentuk nilai kepercayaan kepada user. Dimana pengguna sistem atau user akan menerima hasil dari konsultasi dan juga mengetahui nilai kepercayaan yang diinformasikan oleh pakar melalui sistem.

\section{Metode Penelitian Identifikasi Masalah}

Ruang lingkup dalam mendiagnosa tahapan pengguna narkoba ini dengan membedakan adanya 3 tahapan pengguna narkoba yaitu:
a. Tahapan coba-coba
b. Tahapan tetap
c. Tahapan kecanduan

Analisis Masalah

Memahami permasalahan serta batasan-batasan yang ada pada penelitian. Dan diharapkan sistem yang dibuat nantinya mampu memberikan solusi dalam mendiagnosa tahapan pengguna narkoba.

\section{Menentukan Tujuan}

Berfungsi untuk memperjelas kerangka kerja serta ruang lingkup dari penelitian. Serta bagaimana sasaran dari penelitian tentang mendiagnosa tahapan pengguna narkoba tersebut dapat tercapai.

\section{Mengumpulkan dan Analisa Data}

Tahapan ini dilakukan pengumpulan data-data beserta informasi-informasi, guna mempermudah kajian pada penelitian. Dari data informasi tersebut peneliti dapat mengetahui tahapan-tahapan pengguna narkoba dan apa saja gejalanya, serta langkah pencegahan atau penanggulangan yang akan diambil nantinya. Data penelitian ini diperoleh dari hasil observasi melalui narasumber yang mengetahui lebih luas mengenai topik penelitian ini yaitu BNNP Sumatera Barat, serta dilakukan interview kepada narasumber untuk mencocokan data atau informasi yang didapat.

\section{Metode Forward Chaining}

Bagian-bagian dari sistem yang terdapat pada metode ini, diantaranya :

a. Basis pengetahuan (Knowledge Base) Pembangunan sistem basis ini melalui pengetahuan yang berbasis aturan, kemudian dipresentasikan dengan tata aturan If-Then. Basis pengetahuan adalah konfigurasi tertentu mengenai sebuah pengetahuan, yang dalam proses pengerjaannya ditampilkan dalam bentuk flowchart. Basis pengetahuan ini meliputi fakta, aturan, dan tabel keputusannya dalam diagnosa tahapan pengguna narkoba.

b. Mesin Inferensi. Dimana data pengguna atau user diinputkan ke dalam sistem kemudian di proses berdasarkan fakta-fakta yang ada, serta dilakukan proses pelacakan melalui sistem pakar untuk mendapatkan suatu tujuan atau kesimpulan.

\section{Metode Certainty Factor}

Sebuah metode untuk menentukan nilai keakuratan atau derajat kepercayaan terhadap sebuah fakta yang diolah dengan sistem pakar

\section{Desain Sistem}

Yaitu merancangan suatu bentuk sistem untuk mendiagnosa tahapan pengguna narkoba. $\mathrm{Di}$ dalam proses perancangan desain sistem tersebut terdapat beberapa faktor penunjang yang dibutuhkan dalam pembentukannya, diantaranya :

a. Perancangan Database. Dalam pembentukan database pada penelitian ini meliputi berbagai alur dari context diagram, data flow diagram, serta entity relationship diagram.

b. Penyusunan Basis Data. Basis data adalah pengorganisasian antara satu data dengan data lainnya guna memudahkan dalam memperoleh informasi, serta dapat dijalankan oleh user dan admin disaat penggunaan sistem.

c. Perancangan Struktur Tabel. Setelah peneliti melakukan perancangan basis data, kemudian dirancanglah berupa struktur tabel yang berfungsi dalam menentukan entitas dan atribut yang perlu dan 
dibutuhkan dalam merancangan sistem pakar.

d. Perancangan Interface . Pada tahapan ini, program tampilan antarmuka atau user interface dirancang dengan seefisien mugkin. Sehingga ketika dilakukan proses pengujian sistem, user dapat memahi secara mudah dari tahapan serta langkah kerja dari program tersebut.

\section{Implementasi Sistem}

Tujuan dari implementasi sistem yakninya untuk mengetahui keahlian dari sistem yang dibentuk, apakah sistem yang dirancang oleh peneliti tersebut bisa berdampak positif dalam pengaplikasianya.

\section{Pengujian Sistem}

Pengujian sistem bertujuan untuk mengetahui apabila sistem pakar yang dirancang sudah mencapai sasaran, dan apakah sudah sesuai dengan kaedah dari penelitian. Adapun beberapa mekanisme yang digunakan dalam sebuah sistem diantaranya :

a. Pengujian sistem ini menggunakan bahasa pemrograman PHP MySQL.

b. Hasil dari pengujian sistem ini berdasarkan data-data mengenai tahapan pengguna narkoba beserta cara pananggulangannya.

c. Analisa kerja dari pengujian sistem dengan cara menjawab urutan pertanyaan berdasarkan gejala-gejala tahapan pengguna narkoba dengan menggunakan chekbox, yang ditampilkan sistem.

\section{HASIL DAN PEMBAHASAN}

Setelah melakukan analisa sistem dan proses perancangan aplikasi Sistem pakar maka selanjutnya dilakukan tahapan implementasi sistem. Tahap implementasi sistem ini akan menjelaskan bagaimana langkah-langkah pengoperasian Sistem Pakar dalam melakukan diagnosa tahapan penggunaan narkoba. Implementasi serta penerapan aplikasinya dengan bahasa pemrograman php.

Tahapan pengujian sistem aplikasi ini dimana pasien atau user akan melakukan konsultasi melalui aplikasi sistem pakar yang dirancang. Dimana user terlebih dahulu harus mengisi form input data pasien yang terdiri dari nama, jenis kelamin, alamat, serta tanggal konsultasi sehingga nantinya akan tersimpan ke dalam database.

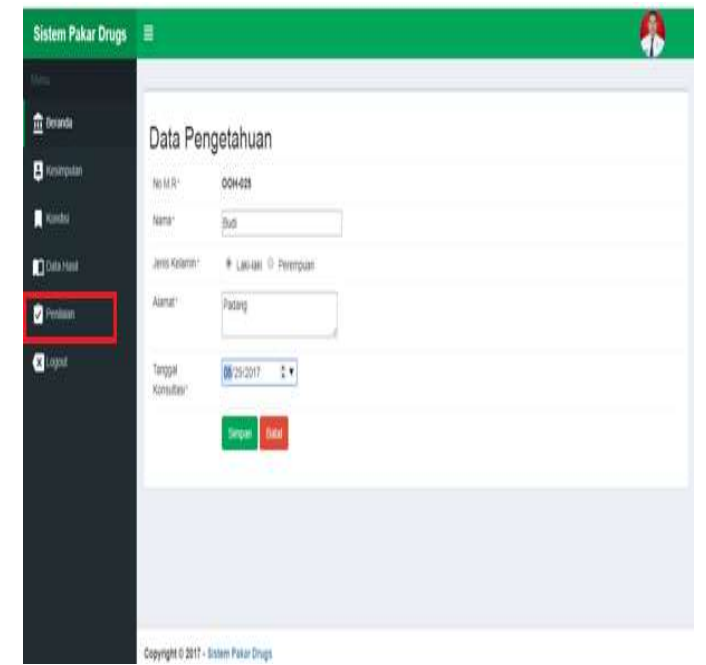

Gambar 1. Form Input Biodata Pasien

Berdasarkan pada gambar diatas, pada form input biodata pasien maka secara otomatis data user akan tersimpan kedalam database, lalu diarahkan pada pemilihan golongan narkoba yang digunakan, seperti pada gambar dibawah ini.

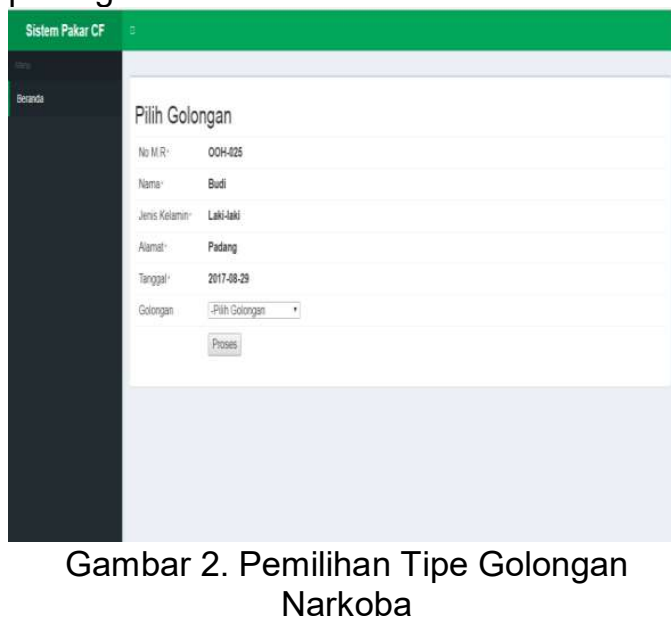

Setelah user memilih golongan narkoba yang digunakan maka user akan diarahkan kedalam penilaian diagnosa. Disana user akan memilih data gejala-gejala yang mereka rasakan agar diproses guna menemukan tahapan penggunaan narkoba yang mereka cari beserta nilai kepastian dari diagnosa tersebut. 


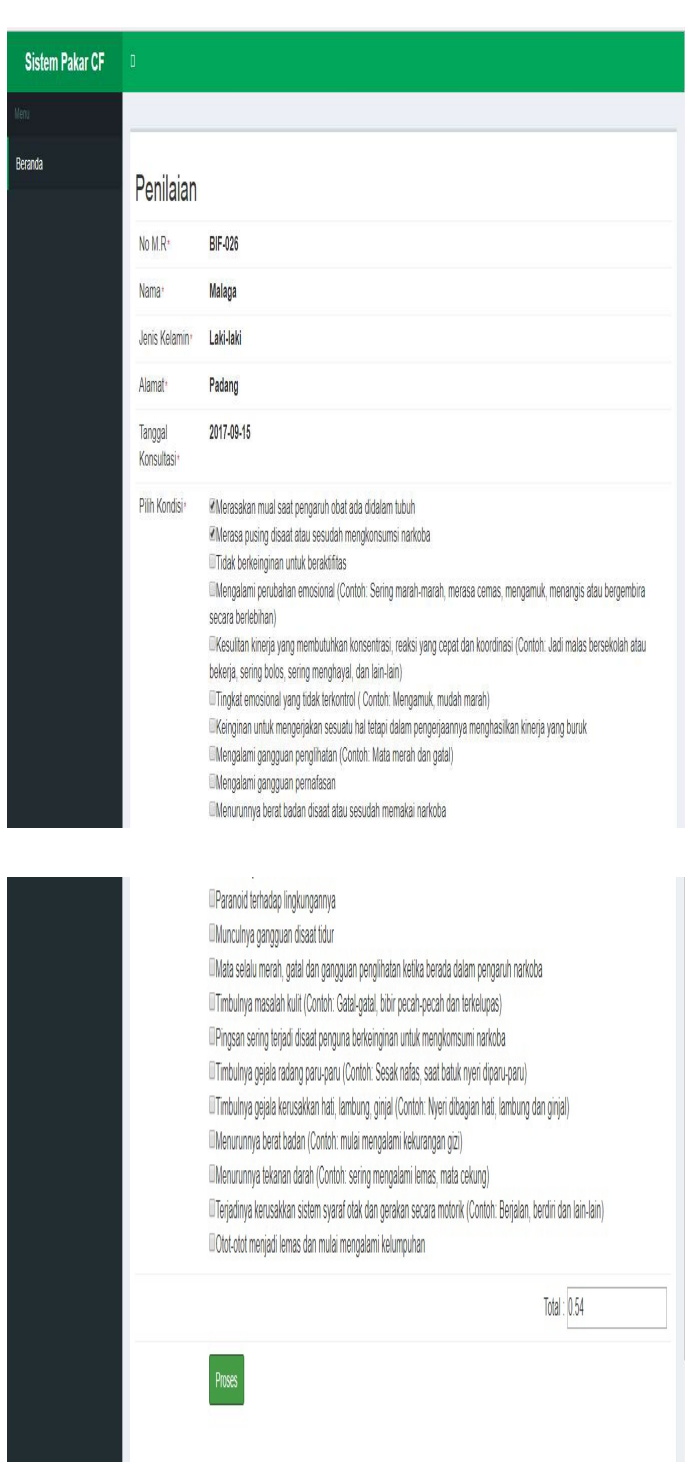

Gambar 3. Form Pemilihan kondisi yang dirasakan

Pada gambar diatas menjelaskan bahwa user pada form pemilihan gejala penggunaan narkoba tersebut sedang memilih penilaian kondisi yang cocok dengan gejala yang dirasakan, proses konsultasi user dengan aplikasi sistem pakar, dan sistem pakar akan memberikan jawaban atau hasil keluaran yang ditemukan pada kondisi user atau pasien.

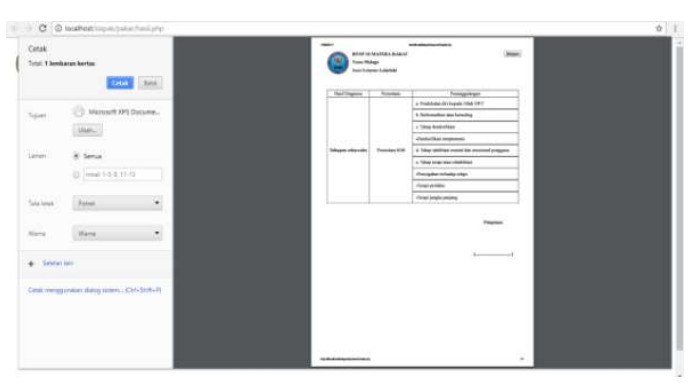

Gambar 4. Hasil Diagnosa

Gambar diatas menjelaskan bahwa telah didapatkan hasil dari penilaian diagnosa oleh user atau pasien, sehingga admin bisa mencetak hasil berupa printout.

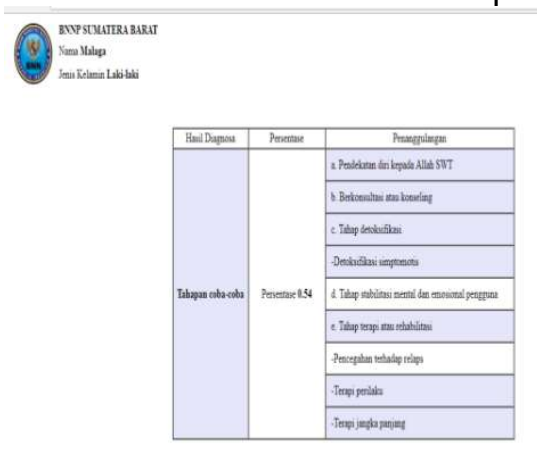

Gambar 5. Data disimpan Pada Database

Menjelaskan hasil penilaian diagnosa tersebut akan disimpan kedalam database dan akan ditampilkan pada data hasil konsultasi secara keseluruhan oleh admin, sehingga admin akan mengetahui jumlah pasien yang menggunakan aplikasi sistem pakar tersebut.

\section{KESIMPULAN}

Dari penjelasan dan hasil penelitian yang sudah dilakukan dalam laporan ini, maka dapat diperoleh kesimpulan sebagai berikut:

1. Dengan menggunakan metode Forward Chaining dan Certainty Factor pada aplikasi Sistem Pakar, proses diagnosa tahapan penggunaan narkoba pada penelitian ini dapat dilakukan secara komputerisasi dan meminimalisir biaya. Dimana pada proses diagnosa terdapat data-data gejala beserta tahapan penggunaan narkoba berdasarkan metode Forward Chaining yang apabila user melakukan konsultasi maka akan ditampilkan hasil diagnosa tersebut dan didukung dengan nilai Certainty Factor atau nilai persentase 
kemungkinan tahapan seseorang pengguna narkoba tersebut.

2. Mengimplementasikan metode Certainty Factor sebagai penunjang didalam mengetahui besaran kepercayaan suatu hasil diagnosa dalam aplikasi sistem pakar.

3. Dan tujuan terpenting didalam perancangan aplikasi sistem pakar mendiagnosa tahapan pengguna narkoba ini yaitu menyadarkan mayarakat akan bahaya dan dampak negatif yang ada pada zat yang terkandung didalam narkoba tersebut.

\section{Referensi}

Deby Saputra. et al, (2015), "Sistem Pakar Untuk Diagnosa Penyakit Kucing Berbasis WEB Menggunakan Framework Codeigniter". Jurnal SCRIPT Vol. 3 No.1 Desember 2015, Hal. 29-38.

Ferdio Grady Susanto. et al, (2015), "Aplikasi Metode Forward Chaining Untuk Mengidentifikasi Jenis Penyakit Pada Kucing Persia ". SNASTIA 2015-10-24, Hal. 1-5.

Feriani A. Tarigan (2014), "Sistem Pakar Untuk Mendiagnosa Penyakit Ginjal dengan Metode Backward Chaining". Jurnal TIMES, Vol III No 2 : 25-29, 2015, ISSN : 23373601.

Jogiyanto. (2003), "Pengembangan Sistem Pakar Menggunakan Visual Basic". Yogyakarta: Andi Yogyakarta.

Johni S, Pasaribu. (2015), “Implementasi Sistem Pakar Untuk Diagnosa Penyakit Mata Pada Manusia". Seminar Nasional Teknologi Informasi dan Komunikasi 2015 (SENTIKA 2015), Hal. 43-50. ISSN : 2089-9815.

Madiha Guftar and Usman Qamar. (2015), "A Rule Based Expert System for Syncope Prediction". SAI Intelligent System Conference 2015, Hal. 559-564.
Saefudin and YG. Rosi Tri Rianti. (2015), "Sistem Pakar Untuk Mendiagnosa Gangguan Pencernaan Pada Anak Dengan Metode Forward Chaining". Jurnal Sistem Informasi Volume. 2, 2015, Hal. 13-16.

Sergey A, Mityagin. et al, (2014), "MultiFactorial Predictive Modelling of Drug Addiction for Large Urban Areas ". ITMO University.

Sholihah. (2015), “Efektivitas Program P4GN Terhadap Pencegahan Penyalahgunaan NAPZA ". Jurnal Kesehatan Masyarakat, Hal. 153159 ISSN : 1858-1196.

Wiwi Verina. (2015), "Penerapan Metode Forward Chaining untuk Mendeteksi Penyakit THT'. Jatisi, Vol. 1 No. 2 Maret 2015, Hal. 123138. 